\title{
Numerical study of pile-up in bulk metallic glass during spherical indentation
}

\begin{abstract}
Al Ke \& DAI LanHong ${ }^{\dagger}$
State Key Laboratory of Nonlinear Mechanics, Institute of Mechanics, Chinese Academy of Sciences, Beijing 100080, China

Pile-up around indenter is usually observed during instrumented indentation tests on bulk metallic glass. Neglecting the pile-up effect may lead to errors in evaluating hardness, Young's modulus, stress-strain response, etc. Finite element analysis was employed to implement numerical simulation of spherical indentation tests on bulk metallic glass. A new model was proposed to describe the pile-up effect. By using this new model, the contact radius and hardness of $\mathrm{Zr}_{41.2} \mathrm{Ti}_{13.8} \mathrm{Cu}_{12.5} \mathrm{Ni}_{10} \mathrm{Be}_{22.5}$ bulk metallic glass were obtained under several different indenter loads with pile-up, and the results agree well with the data generated by numerical simulation.
\end{abstract}

bulk metallic glass, spherical indenter, pile-up, contact radius, hardness

Due to the unique physical, mechanical, and chemical properties, bulk metallic glasses (BMGs) are considered to be a class of very promising structure materials and will be adopted for application in various fields, such as civil astronautics, civil aeronautics and defense ${ }^{[1-5]}$. However, inhomogeneous flow of metallic glasses at room temperature is generally associated with highly localized shear bands ${ }^{[6,7]}$. The formation and interaction of shear bands control the mechanical properties, such as ductility and fracture toughness. Recently, Wang et al. have shown that high density, frequent interacting and arresting events of shear bands can lead to super-plasticity of BMGs at room temperature $^{[8]}$. However, when BMGs are loaded under an unconstrained condition, such as in uniaxial tension or simple shear, rather few of shear bands can be induced. Once the shear bands are formed, BMGs fail catastrophically within the main shear band and show little plasticity ${ }^{[9-11]}$, thus limiting the application of BMGs as engineering material. So, for the sake of perceiving the plastic instability behavior and applications in engineering, much effort has been devoted to the mechanism of formation and evolution of shear bands in BMGs ${ }^{[12-18]}$. In recent years, a depth-sensing indentation technique has been proved to be a powerful tool for investigating the material properties such as hardness, elastic modulus, stress-strain response, etc. ${ }^{[19,20]}$. Recently, increasing efforts

Received April 2, 2007; accepted December 11, 2007

doi: 10.1007/s11433-008-0043-4

${ }^{\dagger}$ Corresponding author (email: 1hdai@lnm.imech.ac.cn)

Supported by the National Natural Science Foundation of China (Grant Nos. 10725211, 10721202 and 10472119) and the Key Project of Chinese Academy of Sciences (Grant Nos. KJCX2-YW-M04 and KJCX-SW-L08) 
have been made to adopt this technique to study the deformation behavior of BMGs ${ }^{[21-24]}$. Pile-ups around the indenter are usually observed in indentation tests of $\mathrm{BMGs}^{25,26]}$. And neglecting the pile-up effect may lead to errors in evaluating hardness and stress-strain response. To take account of the effect, some empirical and semi-empirical formulas have been developed through theoretical analyses and numerical simulations. Matthews ${ }^{[27]}$ and Hill et al. ${ }^{[28]}$ independently developed the relationship between the work-hardening exponent and the height of pile-up; Cheng \& Cheng ${ }^{[20]}$ obtained an equation to compute the contact depth involving pile-up by dimensional analysis; Tuck et al. ${ }^{[29]}$ introduced the energy method to handle the pile-up effect. Although considerable achievements in this field have been made during past decades, further work is needed to investigate the mechanism of pile-up formation and the effect of pile-up on the characterization of the hardness as well as the stress-strain response.

The understanding of elasto-plastic deformation mode at indentation is important to the pile-up problem. However, in real indentation tests, the deformation during loading and unloading cannot be obtained. To overcome this barrier, finite element analysis (FEA) can be performed ${ }^{[20,30,31]}$, by which the stress and deformation field can be continuously measured. The present work focuses on the pile-up effect at indentation test of $\mathrm{Zr}_{41.2} \mathrm{Ti}_{13.8} \mathrm{Cu}_{12.5} \mathrm{Ni}_{10} \mathrm{Be}_{22.5} \mathrm{BMG}$ by using the FE model of spherical indentation. A new model is proposed to compute the true contact area. By using this model, contact areas and hardness corresponding to different penetration depths are obtained.

\section{New model of the pile-up problem}

The experiments of metal indentation made by Tabor $^{[32]}$ revealed that the unloading process is almost perfectly elastic and the impression formed by a spherical indenter is still spherical with a radius larger than the indenter. So the unloading part of the spherical indentation can be approximately referred to Hertzian ${ }^{[33]}$ contact including two elastic spheres. By comparing the deformation profiles under spherical indenter due to loading and unloading, we proposed a model shown in Figure 1. Curve 1 shows a rigid sphere of radius $R$ driven into a BMG material by a force $P$ to a penetration depth $h_{\mathrm{m}}$. Significant pile-up of material appears around the indenter where the pile-up height $h_{\mathrm{pl}}$ consists of two parts: the elastic deflection $h_{\mathrm{d}}$ and the distance $\bar{h}_{\mathrm{pl}}$ between the peak of the contact zone and the specimen surface. Curve 2 shows the shape after the indenter is unloaded and the material elastically recovers, and the final depth of the residual hardness impression is $h_{\mathrm{f}}$. The corresponding pile-up height is $h_{\mathrm{pu}}$ and the impression radius is $\rho . a_{1}$ and $a_{\mathrm{u}}$ are respectively the contact radius of the two status as mentioned above.

Assume that during the unloading of spherical indentation: (1) the contact radius keeps unchanged, i.e. $a_{1}=a_{\mathrm{u}} ;(2)$ the pile-up height remains unchanged, $h_{\mathrm{pl}}=h_{\mathrm{pu}}$ (will be validated later). In

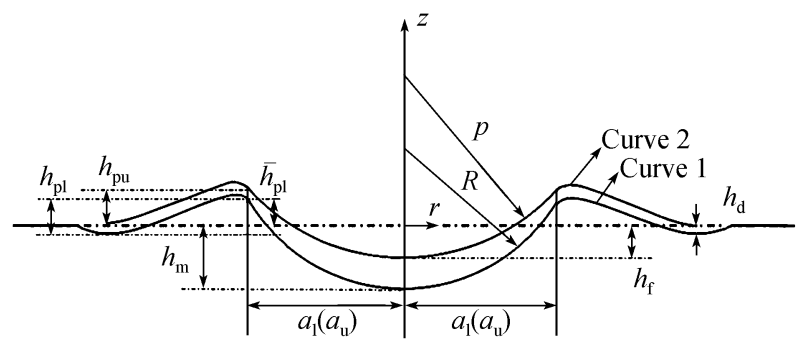

Figure 1 The model of maximum loading and full unloading of spherical indentation. 
accordance with Hertzian contact theory ${ }^{[33]}$, the relationship among contact radius $a$, residual impression radius $\rho$ and indenter radius $R$ must be written as follows:

$$
4 a^{3}\left(\frac{1}{R}-\frac{1}{\rho}\right)=\frac{3 P^{*}}{E^{*}},
$$

where $E^{*}$ is reduced modulus, defined through the equation $\frac{1}{E^{*}}=\frac{1-v_{1}^{2}}{E_{1}}+\frac{1-v_{2}^{2}}{E_{2}} ; P^{*}$ is the load responsible for the elastic deformation of the material beneath the contact region; and $\rho$ is negative for the residue impression is concave. If the load $P$ is considered to be distributed averagely over the plastic zone ${ }^{[34]}$, then $P^{*}$ and $P$ satisfy the following equation:

$$
P^{*}=P\left(\frac{a}{c}\right)^{2}
$$

where $c$ is the radius of the contact zone. Substituting eq. (2) into eq. (1) gives

$$
4 a\left(\frac{1}{R}-\frac{1}{\rho}\right)=\frac{3 P}{E^{*} c^{2}} \text {. }
$$

In real indentation tests, the contact radius $a$ and the unloaded impression radius $\rho$ are both hardly to be recorded, so we need to reconstruct the relationship between $a$ and $\rho$. As shown in Figure 1, according to assumption (2), the maximum contact depth and residual depth satisfy the following geometry relationship:

$$
\left(R-\sqrt{R^{2}-a^{2}}\right)-\left(\rho-\sqrt{\rho^{2}-a^{2}}\right)=h_{\mathrm{m}}-h_{\mathrm{f}}-h_{\mathrm{d}},
$$

where elastic deflection $h_{\mathrm{d}}$ can be obtained by Oliver and Pharr's method ${ }^{[19]}: h_{\mathrm{d}}=\varepsilon(P / S)$, in which $S$ is unloading stiffness, and $\varepsilon$ is a constant dependent on the geometry of the indenter and equal to 0.75 for a spherical indenter. The true contact radius can be obtained through the load-displacement curve with eqs. (3) and (4), so do the material hardness, Young's modulus, and the stress-strain relationship.

\section{Numerical simulation}

By using dimensional analysis, Cheng \& Cheng ${ }^{[20]}$ found that the phenomenon of pile-up depends on the work-hardening exponent $n$, and the ratio of the initial yield strength $\sigma_{\mathrm{y}}$ to Young's modulus $E$. The previous studies have shown that $\sigma_{\mathrm{y}} / E$ of BMGs approaches $2 \%{ }^{[35-37]}$ and $n$ is almost zero ${ }^{[38,39]}$. So we select $\mathrm{Zr}_{41.2} \mathrm{Ti}_{13.8} \mathrm{Cu}_{12.5} \mathrm{Ni}_{10} \mathrm{Be}_{22.5} \mathrm{BMG}\left(\sigma_{\mathrm{y}} / E \approx 1.8 \%\right)$ as a model material and employ a finite element analysis to implement numerical simulation of the spherical indentation test on bulk metallic glass.

Figure 2 shows the mesh by using 14100 axisymmetric, four-node CAX4R elements in ABAQUS Library for the specimen $(\Phi 16 \mathrm{~mm} \times 4 \mathrm{~mm})$ and 96 elements for the spherical indenter (radius $1 \mathrm{~mm}$ ). The constitutive model of the indented material $\left(\mathrm{Zr}_{41.2} \mathrm{Ti}_{13.8} \mathrm{Cu}_{12.5} \mathrm{Ni}_{10} \mathrm{Be}_{22.5} \mathrm{BMG}\right)$ is taken to follow the well-known $\mathrm{J}_{2}$-associated flow theory with isotropic elastic-perfect plastic behavior. Its yield strength is $1.71 \mathrm{GPa}$. Young's modulus and Poisson's ratio are $E_{2}=96 \mathrm{GPa}$ and $v_{2}=0.36^{[38]}$. The indenter is made of diamond with Young's modulus and Poisson's ratio of $E_{1}=$ $1141 \mathrm{GPa}$ and $v_{1}=0.07$, respectively. Roller boundary conditions are applied on the axis of 
symmetry and the bottom surface of the specimen separately. Coulomb friction is used to model the frictional contact between the specimen and the indenter. The friction coefficient is set as 0.2. All simulations are performed by controlling the displacement of the indenter including both the loading and the unloading process.

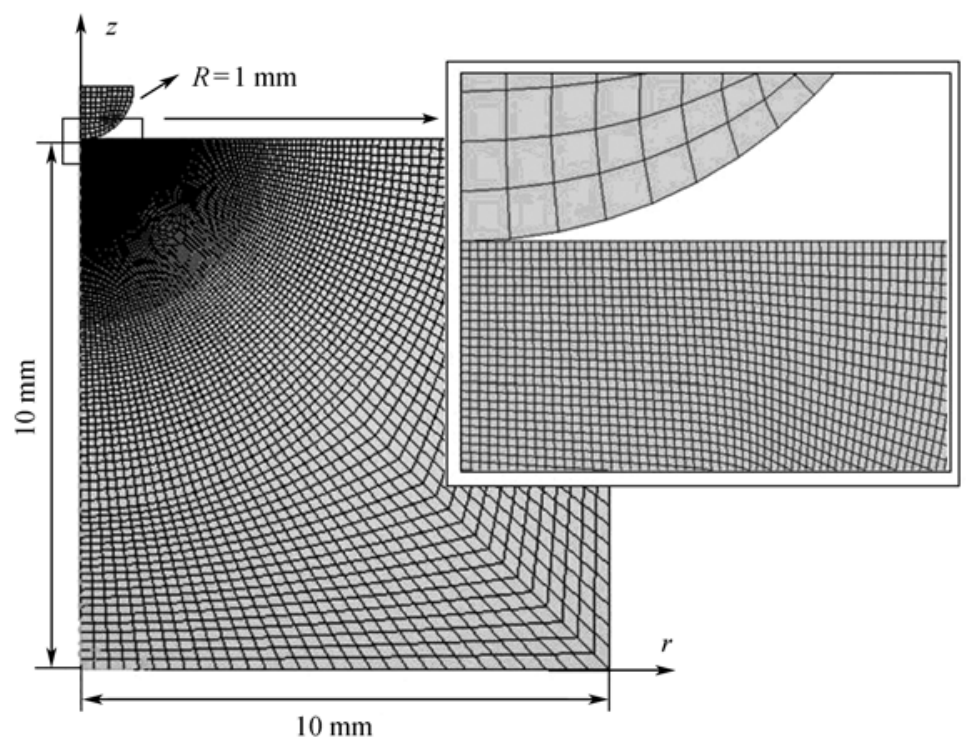

Figure 2 The FE mesh for indentation analysis.

The ratios $h_{\mathrm{m}} / R$ of maximum penetration depth to indenter radius used in the simulations are: 0.1 , $0.15,0.2,0.25,0.3,0.35,0.4,0.45,0.5,0.55$ and 0.6 . The deformation profiles at maximum loading and full unloading are shown in Figure 3 separately, where $a_{\mathrm{m}}$ is the contact radius corresponding to the maximum penetration depth. Obviously pile-ups occur at both maximum loading and full unloading as $h_{\mathrm{m}} / R \geqslant 0.35$. While $h_{\mathrm{m}} / R<0.35$, the elastic deflection $h_{\mathrm{d}}$ is bigger than $\bar{h}_{\mathrm{pu}}$ (see Figure 1) at maximum loading, which is a temporary sink-in phenomenon ${ }^{[40]}$. During the unloading process, the elastic deflection recovers and the pile-up occurs. If the penetration depth
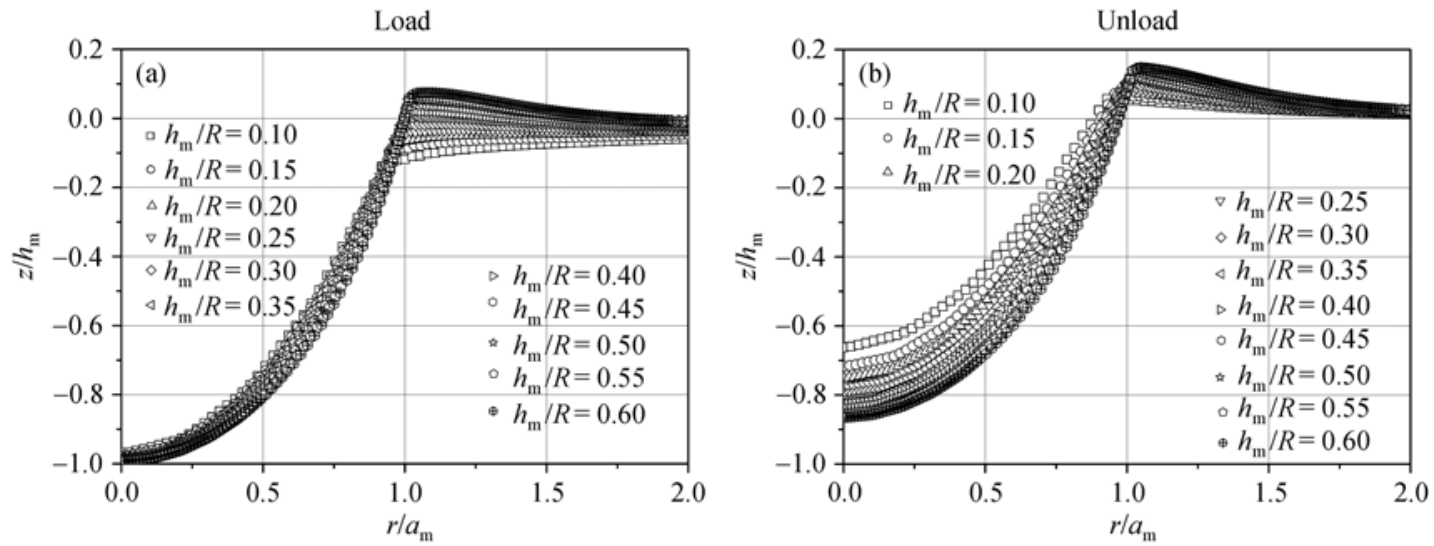

Figure 3 Profile of the spherical indentation at different penetration depths. (a) Maximum loading profile; (b) full unloading profile. 
$h_{\mathrm{m}} / R$ is bigger than 0.32 , there will be no temporary sink-in for $\mathrm{Zr}_{41.2} \mathrm{Ti}_{13.8} \mathrm{Cu}_{12.5} \mathrm{Ni}_{10} \mathrm{Be}_{22.5} \mathrm{BMG}$.

\section{Validation of the two assumptions}

Figure 4(a) depicts the contact radius versus the penetration depth at maximum loading and full unloading. In both cases, the contact radius increases with the increase of penetration depth. Assumption (1) is valid, shown in Figure 4(a). It should be noted that the spherical indenter is not a self-similar indenter. The contact radius $a$ and the penetration depth $h_{\mathrm{m}}$ satisfy the following nonlinear relationship: $a \approx h_{\mathrm{m}} / \tan \beta$, where $\beta$ is the angle between the indenter and the surface of specimen. $\beta$ increases as the penetration depth increases, while the slope of the $a-h_{\mathrm{m}}$ curve decreases.

Figure 4(b) shows the pile-up height versus penetration depth at maximum loading and full unloading, where the former is obtained by the Oliver and Pharr's method ${ }^{[19]}$ as follows: $h_{\mathrm{op}}=h_{\mathrm{m}}-h_{\mathrm{d}}$. Assumption (2) is also true, shown in Figure 4(b). The correctness of the above two assumptions validates our new model. Now we will apply the model to BMGs.
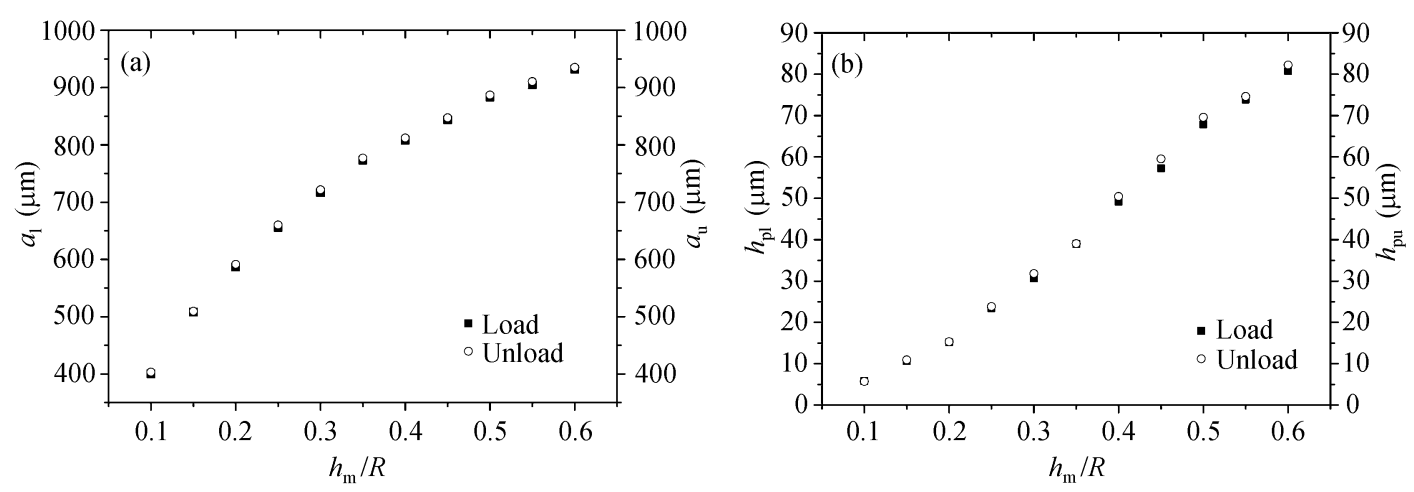

Figure 4 Comparison of the indentation profile at loading and unloading. (a) Contact radius; (b) pile-up height.

\section{Application of the new model}

\subsection{Excluding the pile-up effect}

The contact depth $h_{\mathrm{op}}$ can be obtained by the Oliver and Pharr's method ${ }^{[19]}$. The corresponding contact radius $a_{\mathrm{op}}$ is given by the following geometry relationship: $a_{\mathrm{op}}=\sqrt{R^{2}-\left(R-h_{\mathrm{op}}\right)^{2}}$. Figure 5 shows the relationship between the contact area $a / R$ and the penetration depth $h_{\mathrm{m}} / R$. The quantities are derived from the load-displacement data generated in the finite element simulations and the pile-up effect is not considered. We also acquired the relationship between the true contact radius and true penetration depth. By comparing the two groups of data, it can be seen that the true contact radius would be underestimated if pile-up is neglected. Figure 6 shows the hardness calculated by the two groups of contact radius. Neglecting pile-up may overestimate the true material hardness by as much as $9.79 \%$. Thus, we know the pile-up effect cannot be neglected in the indentation test of BMGs. 


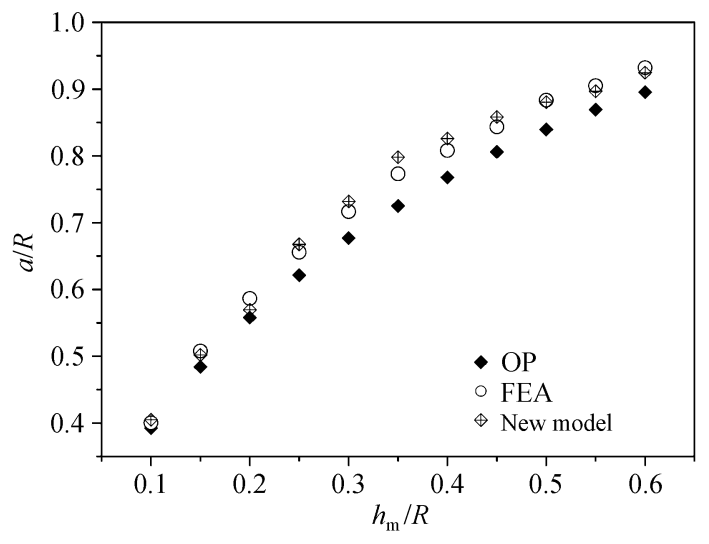

Figure 5 Contact radius at different penetration depths computed by OP method, FEA and our new model.

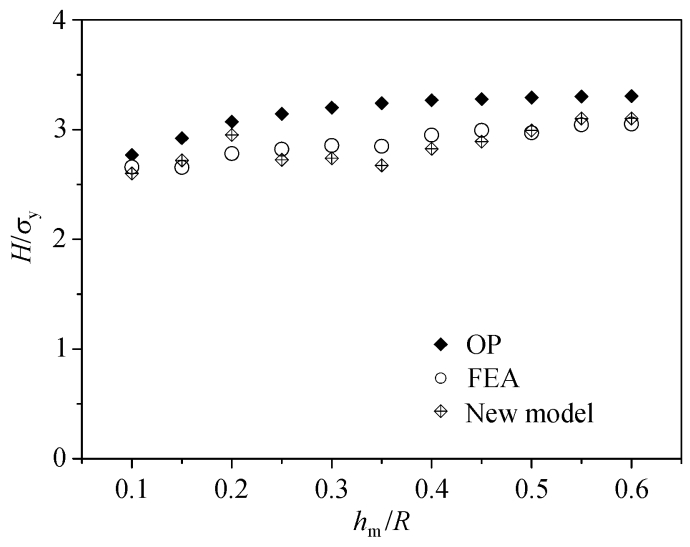

Figure 6 Hardness at different penetration depths computed by OP method, FEA and our new model.

\subsection{Including the pile-up effect}

The radius $c$ of the subindenter plastic zone is given by the expanding cavity model (ECM) developed by Johnson ${ }^{[34]}$ :

$$
C=\left[\frac{3 P}{2 \pi \sigma_{\mathrm{y}}}\right]^{1 / 2} .
$$

Substituting the maximum loads $P$ generated in the finite element simulations into eq. (5) gives the plastic zone radius which is then listed by different $h_{\mathrm{m}} / R$ including $0.1,0.2,0.3,0.4,0.5$ and 0.6 , as shown in Table 1. We also list the true plastic zone radius deduced from the FEA. It can be seen

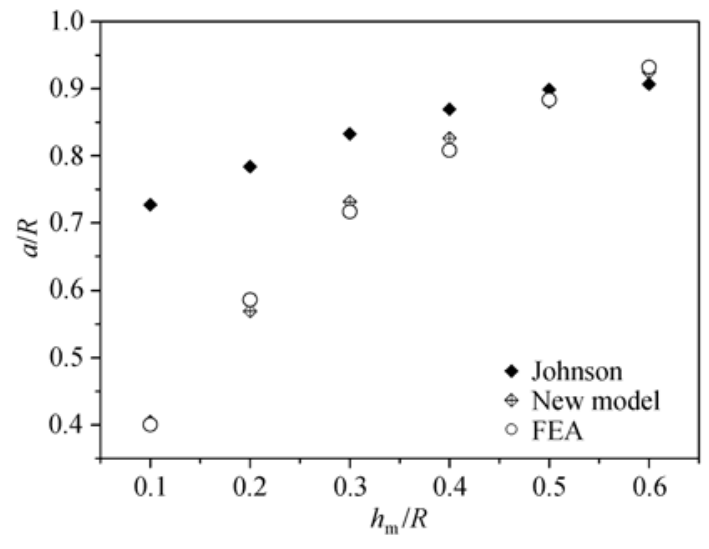

Figure 7 Contact radius obtained through the plastic zone radius (Johnson's formula (5) and FEA separately) and the true value generated by FEA directly. that the plastic zone radius given by eq. (5) is much higher than the true value when $h_{\mathrm{m}} / R<0.5$. Substituting the two groups of data into eqs. (3) and (4) gives the relationship between $a / R$ and $h_{\mathrm{m}} / R$, as illustrated in Figure 7. Comparing the two groups of contact radius with the true radius directly read from FEA, we can see the value given by eq. (5) is much higher than the true value, while the other given by the true plastic zone radius agrees well with the true one. Thus we know the precision of the subindenter plastic zone radius is important to the new model, so we need a better formula to calculate the radius.

Fitting the FEA data of several $h_{\mathrm{m}} / R(0.1,0.2$, $0.3,0.4,0.5$ and 0.6 ), we get the relationship

Table 1 Radius of the plastic zone at different penetration depths computed by Johnson's formula and FEA

\begin{tabular}{ccccccc}
\hline$h_{\mathrm{m}} / R$ & 0.1 & 0.2 & 0.3 & 0.4 & 0.5 & 0.6 \\
\hline Johnson $(\mu \mathrm{m})$ & 799.6 & 1198.0 & 1483.3 & 1670.0 & 1865.2 & 1994.0 \\
FEA $(\mu \mathrm{m})$ & 479.3 & 826.8 & 1258.6 & 1556.1 & 1756.0 & 2037.0 \\
\hline
\end{tabular}


between the plastic zone radius $c$ and the load $P$ of $\mathrm{Zr}_{41.2} \mathrm{Ti}_{13.8} \mathrm{Cu}_{12.5} \mathrm{Ni}_{10} \mathrm{Be}_{22.5} \mathrm{BMG}$ :

$$
\frac{C}{R}=B\left(\frac{P}{\sigma_{\mathrm{y}} R^{2}}\right)^{m},
$$

where $B$ and $m$ are both constants, $B=0.352$, and $m=0.822$. Eq. (6) is validated by using the contact radius computed by our new model where $h_{\mathrm{m}} / R$ are $0.15,0.25,0.35,0.45$ and 0.55 , as shown in Figure 5 . The consistency between the results and the true values generated by FEA shows that eq. (6) is universally suitable to $\mathrm{Zr}_{41.2} \mathrm{Ti}_{13.8} \mathrm{Cu}_{12.5} \mathrm{Ni}_{10} \mathrm{Be}_{22.5} \mathrm{BMG}$. It should be noted that our model is inapplicable to shallow indentation $\left(h_{\mathrm{m}} / R<0.1\right)$, because the contact zone radius cannot be obtained accurately while the material beneath the indenter is not fully plastic state ${ }^{[34]}$ at shallow indentation.

Substituting eq. (6) into eq. (3) gives the relationship between $a$ and $\rho$ :

$$
4 a\left(\frac{1}{R}-\frac{1}{\rho}\right)=\frac{3}{A^{2}} \frac{\sigma_{\mathrm{y}}}{E^{*}}\left(\frac{P}{R^{2} \sigma_{\mathrm{y}}}\right)^{1-2 m} .
$$

Using eqs. (4) and (7), the true contact radius of $\mathrm{Zr}_{41.2} \mathrm{Ti}_{13.8} \mathrm{Cu}_{12.5} \mathrm{Ni}_{10} \mathrm{Be}_{22.5}$ BMG with pile-up can be obtained. As shown in Figure 5, the contact radius with pile-up resulting from our new method agrees well with FEA result. Similarly, the hardness shown in Figure 6 holds true with small $(<3 \%)$ corrections. The above results confirm that our new model can provide reliable estimations of contact radius and hardness for the spherical indentation of $Z_{41.2} \mathrm{Ti}_{13.8} \mathrm{Cu}_{12.5} \mathrm{Ni}_{10} \mathrm{Be}_{22.5}$ BMG with pile-up. The model may be applied to other materials with pile-up phenomena if the radius of the plastic zone is known.

\section{Conclusion}

In indentation of BMGs, a significant pile-up can be observed and the effect of pile-up on characterizing the hardness, Young's modulus, and the stress-strain response cannot be neglected. The finite element analysis is performed to simulate the spherical indentation at different penetration depths. And a new model considering the pile-up effect is proposed and then verified by the indentation of $\mathrm{Zr}_{41.2} \mathrm{Ti}_{13.8} \mathrm{Cu}_{12.5} \mathrm{Ni}_{10} \mathrm{Be}_{22.5}$ BMG. The resulting contact areas and hardness corresponding to different penetration depths agree well with the numerical simulation.

1 Johnson W L. Bulk glass-forming metallic alloys: Science and technology. MRS Bull, 1999, 24: 42-56

2 Inoue A. Stabilization of metallic supercooled liquid and bulk amorphous alloys. Acta Mater, 2000, 48: 279-306[DOI]

3 Wang W H, Dong C, Shek C H. Bulk metallic glasses. Mat Sci Eng R, 2004, 44: 45 - 89[DOI]

4 Eckert J, Das J, Pauly S, et al. Mechanical properties of bulk metallic glasses and composites. J Mater Res, 2007, 22(2): 285$301[\mathrm{DOI}]$

5 Hui X D, Chen G L. Bulk Metallic Glass (in Chinese). Beijing: Chemical Industry Publishing House, 2006

6 Spaepen F. A microscopic mechanism for steady state inhomogeneous flow in metallic glasses. Acta Metall, 1977, 25: 407$415[\mathrm{DOI}]$

7 Hufnagel T C, EI-Deiry P, Vinci R P. Development of shear band structure during deformation of a $\mathrm{Zr}_{57} \mathrm{Ti}_{5} \mathrm{Cu}_{20} \mathrm{Ni}_{8} \mathrm{Al}_{10}$ bulk metallic glass. Script Mater, 2000, 43(12): 1071-1075[DOI]

8 Liu Y H, Wang G, Wang W H, et al. Super plastic bulk metallic glasses at room temperature. Science, 2007, 315: 1385$1388[\mathrm{DOI}]$

9 Zhang Z F, Eckert J, Schultz L. Difference in compressive and tensile fracture mechanisms of $\mathrm{Zr}_{59} \mathrm{Cu}_{20} \mathrm{Al}_{10} \mathrm{Ni}_{8} \mathrm{Ti}_{3}$ bulk metallic glass. Acta Mater, 2003, 51: 1167-1179[DOI]

10 Liu L F, Dai L H, Bai Y L, et al. Characterization of rate-dependent shear behavior of Zr-based bulk metallic glass using 
shear-punch testing. J Mater Res, 2006, 21(1): 153-160[DOI]

11 Liu L F, Dai L H, Bai Y L, et al. Initiation and propagation of shear bands in Zr-based bulk metallic glass under quasi-static and dynamic shear loadings. J Non-Cryst Solids, 2005, 351: 3259-3270[DOI]

12 Zhang T, Inoue A. Thermal and mechanical properties of Ti-Ni-Cu-Sn amorphous alloys with a wide supercooled liquid region before crystallization. Mater Trans JIM, 1998, 39(10): 1001-1006

$13 \mathrm{Hu} \mathrm{X,} \mathrm{Ng} \mathrm{S} \mathrm{C,} \mathrm{Li} \mathrm{Y,} \mathrm{et} \mathrm{al.} \mathrm{Cooling-rate} \mathrm{dependence} \mathrm{of} \mathrm{the} \mathrm{density} \mathrm{of} \mathrm{Pd}_{40} \mathrm{Ni}_{10} \mathrm{Cu}_{30} \mathrm{P}_{20}$ bulk metallic glass. Phys Rev B, 2001, 64(17): 172201[DOI]

14 Dai L H, Yan M, Liu L F, et al. Adiabatic shear banding instability in bulk metallic glasses. Appl Phys Lett, 2005, 87(14): 141916[DOI]

15 Yao K F, Zhang C Q. Fe-based bulk metallic glass with high plasticity. Appl Phys Lett, 2007, 90(6): 061901[DOI]

16 Jiang Q K, Zhang G Q, Jiang J Z, et al. Glass formability, thermal stability and mechanical properties of La-based bulk metallic glasses. J Alloy Compd, 2006, 424(1-2): 183-186[DOI]

17 Fu H M, Wang H, Zhang H F, et al. In situ TiB-reinforced Cu-based bulk metallic glass composites. Script Mater, 2006, 54(11): 1961-1966[DOI]

18 Chen Q J, Shen J, Zhang D L, et al. Mechanical performance and fracture behavior of $\mathrm{Fe}_{41} \mathrm{Co}_{7} \mathrm{Cr}_{15} \mathrm{Mo}_{14} \mathrm{Y}_{2} \mathrm{C}_{15} \mathrm{~B}_{6}$ bulk metallic glass. J Mater Res, 2007, 22(2): 358-363[DOI]

19 Oliver W C, Pharr G M. An improved technique for determining hardness and elastic modulus using load and displacement sensing indentation experiments. J Mater Res, 1992, 7(6): 1564-1583[DOI]

20 Cheng Y T, Cheng C M. Scaling, dimensional analysis, and indentation measurements. Mater Sci Eng R, 2004, 44: $91-149$ [DOI]

21 Schuh C A, Nieh T G. A nanoindentation study of serrated flow in bulk metallic glasses. Acta Mater, 2003, 51: 87-99 [DOI]

22 Zhang H W, Jing X N, Subhash G, et al. Investigation of shear band evolution in amorphous alloys beneath a Vickers indentation. Acta Mater, 2005, 53: 3849-3859 [DOI]

23 Wei B C, Zhang L C, Zhang T H, et al. Strain rate dependence of plastic flow in Ce-based bulk metallic glass during nanoindentation. J Mater Res, 2007, 22(2): 258-263[DOI]

$24 \mathrm{Li} \mathrm{W} \mathrm{H}$, Zhang T H, Wei B C, et al. Instrumented indentation study of plastic deformation in bulk metallic glasses. J Mater Res, 2006, 21(1): 75-81[DOI]

25 Bhowmich R, Raghavan R, Chattopadhyay K, et al. Plastic flow softening in a bulk metallic glass. Acta Mater, 2006, 54: $4221-4228[\mathrm{DOI}]$

26 Liu L, Chan K C. Plastic deformation of Zr-based bulk metallic glasses under nanoindentation. Mater Lett, 2005, 59: 30903094[DOI]

27 Matthews J R. Indentation hardness and hot pressing. Acta Metall, 1980, 28: 311-318[DOI]

28 Hill R, Storkers R, Zdunek A B. A theoretical study of the Brinell hardness test. Proc R Soc London A, 1989, 423: 301-330

29 Tuck J R, Korsunsky A M, Bull S J, et al. On the application of the work-of-indentation approach to depth-sensing indentation experiments in coated systems. Surf Coat Tech, 2001, 137: 217-224[DOI]

30 Taljat B, Zacharia T. New analytical procedure to determine stress-strain curve from spherical indentation data. Int J Solids Struct, 1998, 35(33): 4411-4426[DOI]

31 Hernot X, Bartier O, Bekouche Y, et al. Influence of penetration depth and mechanical properties on contact radius determination for spherical indentation. Int J Solids Struct, 2006, 43: 4136-4153[DOI]

32 Tabor D. A simple theory of static and dynamic hardness. Proc R Soc London A-Math Phys, 1948, 192(1029): 247-274

33 Hertz H. On the Contact of Elastic Solids. London: Macmillan, 1896

34 Johnson K L. Contact Mechanics. Cambridge: Cambridge University Press, 1985

35 Johnson W L, Samwer K. A universal criterion for plastic yielding of metallic glasses with a $\left(T=T_{\mathrm{g}}\right) 2 / 3$ temperature dependence. Phys Rev Lett, 2005, 95: 195501[DOI]

36 Yang B, Liu C T, Nieh T G. Unified equation for the strength of bulk metallic glasses. Appl Phys Lett, 2006, 88: 221911 [DOI]

37 Kameda J, Yokoyama Y, Allen T R. Strain-controlling mechanical behavior in noncrystalline materials (I): Onset of plastic deformation. Mat Sci Eng A, 2007, 448: 235-241[DOI]

38 Liu L F, Dai L H, Bai Y L, et al. Behavior of multiple shear bands in Zr-based bulk metallic glass. Mater Chem Phys, 2005, 93: $174-177[\mathrm{DOI}]$

39 Trichy G R, Scattergood R O, Koch C C, et al. Ball indentation tests for a Zr-based bulk metallic glass. Script Mater, 2005, 53(12): 1461-1465[DOI]

40 Kim S H, Baik M K, Kwon D. Determination of precise indentation flow properties of metallic materials through analysis contact characteristics beneath indenter. J Eng Mater-T ASME, 2005, 127: 265-272[DOI] 